\title{
Development and Validation of Tongue Diagnostic Parameters-Based Diagnostic Signatures in Coronary Artery Disease Patients with Clopidogrel Resistance after Percutaneous Coronary Intervention
}

\section{Bo Liang}

Nanjing University of Chinese Medicine

Cai-Hong Liang

Nanjing Medical University

Jia Lu

Nanjing University of Chinese Medicine

Ning Gu ( $20193122 @ n j u c m . e d u . c n$ )

Nanjing University of Chinese Medicine https://orcid.org/0000-0003-0704-6768

Original investigation

Keywords: tongue diagnostic parameters, diagnostic signatures, coronary artery disease, clopidogrel resistance, percutaneous coronary intervention

Posted Date: August 4th, 2020

DOI: https://doi.org/10.21203/rs.3.rs-42380/v1

License: (c) (i) This work is licensed under a Creative Commons Attribution 4.0 International License. Read Full License 


\section{Abstract}

Background: Credible diagnostic stratification remains a challenge for coronary artery disease (CAD) patients with clopidogrel resistance (CR) after percutaneous coronary intervention (PCl). Tongue Diagnostic parameters (TDP)-based diagnostic signatures might predict the diagnostic.

Methods: Clinical and TDP data were obtained from CAD patients with CR after PCl patients and then analyzed. TDP-based diagnostic signatures were developed and validated. Diagnostic prediction was assessed using a receiver operating characteristic (ROC) curve.

Results: A total of 101 patients were consecutively identified. Then, TDP were identified as significantly associated with $\mathrm{CR}$ diagnostic and were combined with risk factors to develop a model. ROC curve analysis showed that TDP-based diagnostic signatures performed well in diagnosing CR with an area under the ROC curve value of 0.766 .

Conclusions: This study identified and validated a novel TDP-based diagnostic signatures to reliably distinguish CR diagnosis in CAD patients undergone PCl. Further larger, multicenter prospective studies are desired to validate this model.

\section{Introduction}

Cardiovascular disease remains a leading cause of morbidity and mortality, despite improvements in outcomes[1, 2]. Age-adjusted coronary artery disease (CAD) mortality has declined since the 1980s, particularly in high-income regions[3]. However, many risk factors, particularly obesity[4] and diabetes mellitus[5], have been increasing substantially. CAD rates are now still high in many countries. Proverbially, percutaneous coronary intervention $(\mathrm{PCl})$ is one of the best treatments for CAD, not just for acute coronary events[6], often with coronary thrombus formation. Although the guidelines don't yet endorse exactly dual antiplatelet therapy duration after PCI[7, 8], it's worth noting that for now, dual antiplatelet therapy is definitely a must. Aspirin and clopidogrel have become integral parts of management in patients with CAD and after PCl. However, the platelet responses to aspirin and clopidogrel are not uniform[9]. Diminished or lack of response to antiplatelet agents has been termed resistance to antiplatelet therapy[10]. The mechanisms of clopidogrel resistance (CR) include alterations in genetic[11-13], pharmacokinetic[14], and platelet properties[15]. There is a dearth of information in regard to the clinical significance, methods to test them, and strategies to treat them[10]. Further research in preference signatures is necessary for early detection, early diagnosis and early intervention appropriately. The recognition of more sensitive and specific signatures for CR diagnosis is required and is expected to result in a better choice of risk-related therapy. The discovery of preference signatures could improve the prognosis of CAD patients with $\mathrm{CR}$ after $\mathrm{PCl}$ and reduce the burden of constant side effects in surviving individuals.

Traditional Chinese medicine (TCM) has been used in clinical practice for more than two thousand years[16], characterizing whole view and syndrome differentiation, and has shown its unique advantages 
in the prevention, treatment, rehabilitation and health care of various diseases[17, 18]. Moreover, Huoxue Huayu therapy, a kind of TCM therapy, is an effective and safe therapy for CAD patients after PCI[19]. However, none of the studies, so far, suggest whether TCM has diagnostic value for CAD patients with CR after PCl. When such an exciting tongue diagnostic parameters (TDP), a characteristic of TCM, is evaluated combined with risk factors as diagnostic signatures, it is highly possible to inspect an association between TDP and diagnostic classification. Here, we scrutinized the diagnostic significance of TDP-based diagnostic signatures for predicting in CAD patients with CR after PCI.

\section{Methods}

\section{Study Design}

This was a real-world, clinical observation trial conducted at The Affiliated Jiangning Hospital of Nanjing Medical University (Nanjing, China), a large tertiary referral center, to assess the diagnostic value of TDP in CAD patients with CR after PCl. The study was approved by the ethics committee at The Affiliated Jiangning Hospital of Nanjing Medical University (No. 20150221), and patients provided signed written informed consent before enrollment and were able to withdraw from the study at any time and no explanation was required. This clinical trial was performed according to the revised Declaration of Helsinki 2013[20].

\section{Patient Selection}

Participants were continuously recruited from May 2015 until December 2016. Patients were eligible if they were adults between the ages of 18 and 75, diagnosed with CAD and undergone PCI. CAD was defined according to 2019 European Society of Cardiology Guidelines[8] or 2019 guiding principles for chronic total occlusion percutaneous coronary intervention[6]. The exclusion criteria were 1) accompanied by hematological diseases (abnormal coagulation, significantly abnormal prothrombin time, and platelet $<50 \times 10^{9} / \mathrm{L}$ or $\left.>450 \times 10^{9} / \mathrm{L}\right) ; 2$ ) application of drugs that affect coagulation and platelet function, such as warfarin, within 6 months; 3 ) rheumatic heart disease, severe valvular disease, pulmonary heart disease, dilated cardiomyopathy, hypertrophic cardiomyopathy, myocarditis and hyperthyroidism; 4) severe anemia, malignant tumors, severe liver and kidney dysfunction (chronic kidney disease > stage 4, Child-Pugh > level C), severe immune system and respiratory diseases, and organ transplantation. Patients who were allergic to clopidogrel or had contraindications and had a history of surgery or major trauma within 3 months were excluded.

\section{Study Products and Procedure}

After rigorous inclusion and exclusion criteria, patients were divided into two groups: CR group (CR arm) and control group (Con arm). CR was defined according to previous studies[21-23]. All patients were given loading doses of aspirin (300 mg, Bayer, Germany) and clopidogrel (300 mg, Sanofi, France) before 
$\mathrm{PCl}$. All patients received maintenance doses of antiplatelet agents $(100 \mathrm{mg} / \mathrm{d}$ aspirin and $75 \mathrm{mg} / \mathrm{d}$ clopidogrel). All patients were given standardized drug treatment of CAD, combined with other diseases to the corresponding treatment. Thromboelastography (TEG5000, Haemoscope, United States) was performed on the fifth day after PCl. All data were monitored for accuracy.

\section{Identification of Diagnostic Signatures}

Clinical data, laboratory examination, TDP determined by TCM Diagnostics[24] and surgical data were potential diagnostic signatures. The TDP included tongue color, tongue form, tongue coating and sublingual complex. Tongue color was measured by tongue colorimetric plate, which was divided into light white, light red, red crimson and indigo blue, corresponding to grades 0, 1, 2 and 3 . Tongue form was diagnosed according to size (fat, normal and lean), teeth marks and crack. Tongue coating was composited of color (white, yellow, and dark gray measured by tongue colorimetric plate) and proper (thick and thin coating, smooth, moist and dry coating, greasy coating and exfoliative coating). And sublingual complex was classified into 4 grades according to the degree of stasis: Grade 0, normal; Grade 1 , main vein thickened $1 / 5$, slightly bluish color, no obvious dilatation of venous plexus, small nodules, scattered petechiae in sublingual capillaries; Grade 2, main vein thickened 2/5 4/5, bluish purple color, venous plexus obvious rage, nodules beaded or sugar gourd shape; Grade 3, main vein thickened by more than 1 times, dark purple color, venous plexus obvious rage, nodules distension was treetops and clusters. All patients were observed under natural light from 7:00 a.m. to 8:00 a.m. in a quiet and warm environment, without gargling or drinking stimulating or colored liquid food or drugs by 3 fixed physicians with unified training and TCM internal medicine practice qualification. Then, to uncover the practicability and accuracy of diagnosis signatures for $\mathrm{CR}$, risk factors determined by logistic regression analysis were selected. Moreover, TDP, which were different significantly in arms and performed with $\chi^{2}$ test, were also analyzed. A two-tailed significance level of $P \leq 0.05$ was considered statistically significant.

\section{Development and Validation of Diagnostic Signatures}

Finally, diagnostic signatures were established to build a diagnostic prediction formula, and then validated with 20 patients (including $C R$ and non-CR patients) randomly selected by the double-blind method[17]. The result of thromboelastography was considered as the diagnostic standard. After assessed using a time-dependent receiver operating characteristic (ROC) curve, the area under the ROC curve (AUC) values were computed[25].

\section{Results}

\section{Patient Enrollment}

Between May 2015 and December 2016, 116 patients were divided into CR arm (43 patients) or Con arm (73 patients) at The Affiliated Jiangning Hospital of Nanjing Medical University. During the study, 11 
cases were lost ( 5 cases in the CR arm and 6 cases in the Con arm, respectively) and 4 cases ( 1 case in the $\mathrm{CR}$ arm and 3 cases in the Con arm, respectively) were excluded because of incomplete data. Finally, 101 cases (37 cases in the CR arm and 64 cases in the Con arm, respectively) completed this trial (Fig. 1).

\section{Patient characteristics}

Division proved successful with very similar patient characteristics (Table 1). The proportion of hypertension and lipoprotein(a) level in CR arm were higher than those in Con arm $(P=0.0196, P=0.015$, respectively), and fibrinogen level in $\mathrm{CR}$ arm was lower than that in Con arm $(P=0.031)$. There was no significant difference in the distribution of diseased blood vessels between the two groups (all $P>0.05$ ) (Table 1). 
Table 1

Demographic and baseline clinical characteristics.

\begin{tabular}{|c|c|c|c|}
\hline Variables & $\mathrm{CR} \operatorname{arm}(\mathrm{N}=37)$ & Con $\operatorname{arm}(N=64)$ & $P$ \\
\hline Age & $65.86 \pm 8.61$ & $61.95 \pm 10.90$ & 0.0640 \\
\hline Smoking & $9(24 \%)$ & $11(17 \%)$ & 0.3859 \\
\hline Alcohol & $3(8 \%)$ & $6(9 \%)$ & 0.8830 \\
\hline Hypertension & $19(51 \%)$ & $18(28 \%)$ & 0.0196 \\
\hline Diabetes & $8(21 \%)$ & $9(14 \%)$ & 0.3279 \\
\hline Hyperlipidemia & $3(8 \%)$ & $3(4 \%)$ & 0.7919 \\
\hline \multicolumn{4}{|l|}{ Drugs } \\
\hline Statins & $3(8 \%)$ & $4(6 \%)$ & 0.9583 \\
\hline Calcium channel blockers & $6(16 \%)$ & $9(14 \%)$ & 0.7693 \\
\hline Antimicrobials & $2(5 \%)$ & $6(9 \%)$ & 0.7419 \\
\hline \multicolumn{4}{|l|}{ Vessels } \\
\hline Single vessel lesion & $13(35 \%)$ & $20(31 \%)$ & 0.6884 \\
\hline Multivessel lesions & $24(64 \%)$ & $44(68 \%)$ & \\
\hline Left coronary artery & $19(51 \%)$ & $28(43 \%)$ & 0.5969 \\
\hline Right coronary artery & $0(0 \%)$ & $1(1 \%)$ & \\
\hline Both & $18(48 \%)$ & $35(54 \%)$ & \\
\hline Stents & & & 0.1233 \\
\hline One & $23(62 \%)$ & 49 (76\%) & \\
\hline More & $14(37 \%)$ & $15(23 \%)$ & \\
\hline Cardiovascular events & $4(10 \%)$ & $1(1 \%)$ & 0.0589 \\
\hline WBC (109/L) & $6.85 \pm 2.07$ & $7.71 \pm 2.45$ & 0.075 \\
\hline $\mathrm{Hb}(\mathrm{g} / \mathrm{L})$ & $129.32 \pm 16.56$ & $132.83 \pm 18.65$ & 0.346 \\
\hline PLT (109/L) & $161.05 \pm 50.06$ & $170.09 \pm 45.64$ & 0.357 \\
\hline $\mathrm{CRP}(\mathrm{mg} / \mathrm{L})$ & $9.59 \pm 18.97$ & $7.53 \pm 13.85$ & 0.629 \\
\hline $\mathrm{TG}(\mathrm{mmol} / \mathrm{L})$ & $1.96 \pm 1.28$ & $1.99 \pm 1.07$ & 0.918 \\
\hline $\mathrm{TC}(\mathrm{mmol} / \mathrm{L})$ & $3.98 \pm 1.15$ & $4.75 \pm 6.65$ & 0.489 \\
\hline $\mathrm{HDL}-\mathrm{C}(\mathrm{mmol} / \mathrm{L})$ & $1.26 \pm 0.60$ & $1.23 \pm 0.55$ & 0.273 \\
\hline
\end{tabular}




\begin{tabular}{|llll|}
\hline Variables & CR arm $(\mathrm{N}=37)$ & Con arm $(\mathrm{N}=64)$ & $P$ \\
\hline LDL-C (mmol/L) & $2.13 \pm 0.86$ & $1.95 \pm 0.65$ & 0.217 \\
\hline Lpa $(\mathrm{mg} / \mathrm{L})$ & $280.35 \pm 215.06$ & $178.23 \pm 159.76$ & 0.015 \\
\hline Glu $(\mathrm{mmol} / \mathrm{L})$ & $6.60 \pm 2.91$ & $6.14 \pm 1.83$ & 0.329 \\
\hline ALT (U/L) & $29.65 \pm 18.92$ & $30.72 \pm 0.87$ & 0.798 \\
\hline UA (umol/L) & $327.35 \pm 73.56$ & $347.63 \pm 93.57$ & 0.261 \\
\hline BUN (mmol/L) & $5.49 \pm 1.62$ & $6.10 \pm 2.94$ & 0.181 \\
\hline Cr (umol/L) & $81.57 \pm 41.38$ & $75.52 \pm 30.78$ & 0.405 \\
\hline INR & $1.08 \pm 0.25$ & $1.08 \pm 0.11$ & 0.988 \\
\hline FIB (g/L) & $2.87 \pm 1.19$ & $4.40 \pm 0.70$ & 0.031 \\
\hline
\end{tabular}

\section{Identification of Diagnostic Signatures}

Through logistic regression analysis, hypertension ( $\mathrm{OR}=3.115,95 \% \mathrm{Cl}: 1.201 \sim 8.077)$ and low level of fibrinogen ( $O R=1.919,95 \% \mathrm{Cl}: 1.081 \sim 3.408)$ were found to be related to independent risk factors for CR. Lastly, there were no differences in tongue color, tongue form and tongue coating (all $P>0.05$ ) (Table 2). However, $\mathrm{CR}$ arm had a higher classification in tongue color and sublingual complex compared to Con arm $(P<0.05, P<0.01$, respectively) (Table 3$)$. 
Table 2

Tongue diagnostic parameters characteristics.

\begin{tabular}{|c|c|c|c|}
\hline Variables & CR arm & Con arm & $P$ \\
\hline \multicolumn{4}{|c|}{ Tongue form } \\
\hline Size & & & 0.9326 \\
\hline Fat & $18(47 \%)$ & $31(48 \%)$ & \\
\hline Normal & $16(43 \%)$ & $29(45 \%)$ & \\
\hline Lean & $3(8 \%)$ & $4(6 \%)$ & \\
\hline \multicolumn{2}{|c|}{ Teeth marks } & & 0.4129 \\
\hline Yes & $12(32 \%)$ & $26(41 \%)$ & \\
\hline No & $25(68 \%)$ & $38(59 \%)$ & \\
\hline Crack & & & 0.8835 \\
\hline Yes & $5(14 \%)$ & $8(13 \%)$ & \\
\hline No & $32(86 \%)$ & $56(88 \%)$ & \\
\hline \multicolumn{2}{|c|}{ Tongue coating color } & & 0.9274 \\
\hline White & $26(70 \%)$ & $45(70 \%)$ & \\
\hline Yellow & $8(22 \%)$ & $15(23 \%)$ & \\
\hline Dark gray & $3(8 \%)$ & $4(6 \%)$ & \\
\hline \multicolumn{4}{|c|}{ Tongue coating proper } \\
\hline & & & 0.2264 \\
\hline Thick & $8(22 \%)$ & $8(13 \%)$ & \\
\hline \multirow[t]{2}{*}{ Thin } & $29(78 \%)$ & $56(88 \%)$ & \\
\hline & & & 0.9127 \\
\hline Smooth & $18(49 \%)$ & $33(52 \%)$ & \\
\hline Moist & $3(8 \%)$ & $6(9 \%)$ & \\
\hline Dry & $16(43 \%)$ & $25(39 \%)$ & \\
\hline Greasy & & & 0.8732 \\
\hline Yes & $11(30 \%)$ & $20(31 \%)$ & \\
\hline No & $26(70 \%)$ & $44(69 \%)$ & \\
\hline Exfoliative & & & 0.4453 \\
\hline
\end{tabular}




\begin{tabular}{|llll|}
\hline Variables & CR arm & Con arm & $P$ \\
\hline Yes & $6(16 \%)$ & $7(11 \%)$ & \\
\hline No & $31(84 \%)$ & $57(89 \%)$ & \\
\hline
\end{tabular}

Table 3

Tongue diagnostic parameters classification.

\begin{tabular}{|llll|}
\hline Variables & CR arm & Con arm & $P$ \\
\hline Tongue color classification & & & $<0.05$ \\
\hline 0 & 4 & 15 & \\
\hline 1 & 5 & 8 & \\
\hline 2 & 9 & 21 & \\
\hline 3 & 19 & 20 & \\
\hline Sublingual complex classification & & & \\
\hline 0 & 3 & 10 & \\
\hline 1 & 4 & 18 & \\
\hline 2 & 14 & 26 & \\
\hline 3 & 16 & 10 & \\
\hline
\end{tabular}

\section{Development of TDP-Based Diagnostic Signatures}

The ROC curve analysis was performed to compare the sensitivity and specificity of diagnostic prediction in TDP-based diagnostic signatures. The AUC value was obtained from ROC curve analysis. In this study, Model 1 (tongue color classification), Model 2 (sublingual complex classification), Model 3 (Model 1+2) and Model 4 (Model 3 + hypertension + fibrinogen) reached AUC values of 0.613, 0.679, 0.692 and 0.766, respectively (Fig. 2), demonstrating that the diagnostic power of this signatures was credible. In addition, the risk score was calculated according to the signatures as follow: Risk score $=1 /\left[1+\mathrm{e}^{-\left(0.186^{\star} \text { tongue color }\right.}\right.$ classification+0.658*sublingual complex classification+1.252*hypertension+0.718*fibrinogen-4.509)].

\section{Validation of TDP-Based Diagnostic Signatures}

Of 20 patients, 11 cases were CR and 9 cases were non-CR. TDP-based diagnostic signatures correctly diagnosed 9 in CR and 8 in non-CR with an accuracy rate of $81.9 \%$. 


\section{Discussion}

In the last few decades, significant breakthrough has been made in our comprehension of the development and therapy of $\mathrm{CAD}[26]$. As angiography continues to mature, more and more hospitals begin to implement $\mathrm{PCl}$, which also benefits more patients. However, despite the excellent anti-platelet aggregation of dual antiplatelet therapy after $\mathrm{PCl}$, there are still relevant studies showing that the response of platelets to clopidogrel remains highly diverse among individuals[27, 28], and some patients may still suffer from in-stent thrombosis, recurrent myocardial infarction and other ischemic events during the treatment of clopidogrel[23,29]. Hence, it is necessary to determine the biological characteristics regarding $\mathrm{CR}$.

There are several commonly used risk scores for CAD. The GRACE risk score has been developed into an application and it has been integrated into electronic medical records systems used in daily clinical management of ACS patients worldwide. The United Kingdom National Institute for Health and Clinical Excellence guideline has recommended employing the GRACE risk score since 2010[30]. The purpose of CRUSADE Bleeding Score is to help clinicians estimate a patient's baseline risk of in-hospital major bleeding during non-ST-segment elevation myocardial infarction (NSTEMI)[31]. The SYNTAX score is a unique tool to score complexity of CAD[32]. The NERS score II, similar to the conventional NERS score, is more predictive of major adverse cardiac events than the SYNTAX score in unprotected left main coronary artery patients after implantation of a drug-eluting stent[33]. Later, apolipoprotein A1 was identified associated with SYNTAX score in patients with a NSTEMI and apolipoprotein A1 $<1.07 \mathrm{~g} / \mathrm{L}$ may have more complex coronary artery lesions[34]. Recently studies found that lipids[35] ,plasma B-type natriuretic peptide level before $\mathrm{PCI}[36]$ and circulating HtrA2[37] showed promise as a novel potential biomarker for identify ischemia-reperfusion injury after STEMI. The CAMI-NSTEM[38, 39] and SCAMINSTEMI[40] score can serve as a useful tool facilitating rapid risk assessment among a broader spectrum of patients admitted owing to NSTEMI. However, there are no relevant risk scores that can be used to diagnose $\mathrm{CR}$ in CAD patients after PCI. We innovatively developed and validated a TDP-based diagnostic signatures in CAD patients with $\mathrm{CR}$ after $\mathrm{PCl}$ that is not described in the current guidelines. When we combined tongue color classification and sublingual complex classification (Model 3 ), the AUC value is 0.692 . While hypertension and fibrinogen were added into diagnostic signatures, the AUC reached 0.766 , demonstrating that the diagnostic power of this signatures was credible.

Furthermore, we developed and validated a TDP-based diagnostic signatures that is significantly associated with CR prediction, making it a favorable and practical stratified for risk classification in CR. In search of an optimal signature with diagnostic prediction, it could be proven that the diagnostic power of the TDP-based diagnostic signatures is accepted. This useful strategy for the vigorous selection of markers has vast application potential in other diseases. The high diagnostic categorization performance of the TDP-based diagnostic signatures is assuredly due to our idiographic reanalysis strategy. To identify reliable diagnostic signatures of $\mathrm{CR}$, we utilized methods that are specifically designed to perform resolutely. As such, our TDP-based diagnostic signatures model can serve as personalized, single-sample estimate of survival in NBL patients and may be promptly incorporated into clinical utility. 


\section{Conclusions}

Herein, we performed and proposed the first TDP-based diagnostic signatures analysis in CAD patients with $\mathrm{CR}$ after PCl. However, there are not no limitations to this study, although the TDP-based diagnostic signatures is robust. We only included population undergone $\mathrm{PCl}$, so other high-quality clinical evidence is needed before the model is applied to all CAD patients as a clinically useful tool. Moreover, this model included 101 patients from a large tertiary referral center, however, the clinical sample size is relatively small. Therefore, further larger, multicenter prospective studies are desired to validate these findings.

\section{Abbreviations}

AUC: area under the receiver operating characteristic curve, CAD: coronary artery disease, CR: clopidogrel resistance, NSTEMI: non-ST-segment elevation myocardial infarction, PCl: percutaneous coronary intervention, ROC: receiver operating characteristic, TCM: traditional Chinese medicine, TDP: tongue diagnostic parameters.

\section{Declarations}

\section{Ethics approval and consent to participate}

The study was approved by the ethics committee at The Affiliated Jiangning Hospital of Nanjing Medical University (No. 20150221), and patients provided signed written informed consent before enrollment and were able to withdraw from the study at any time and no explanation was required.

\section{Consent for publication}

Not applicable.

\section{Availability of data and materials}

All data generated or analysed during this study are included in this published article.

\section{Competing interests}

The authors declare that they have no competing interests.

\section{Funding}

This work was supported by the National Natural Science Foundation of China [grant number 81774229], Jiangsu Leading Talent Project of Traditional Chinese Medicine [grant number Jiangsu TCM 2018 No.4], 
Major Project of Nanjing Medical Science and Technology Development During 13th Five-year Plan [grant number ZDX16013], and Jiangsu Universities Nursing Advantage Discipline Project [grant number 2019YSHL095].

\section{Authors' contributions}

$\mathrm{BL}$ and $\mathrm{NG}$ conceived, designed, or planned the study. $\mathrm{BL}, \mathrm{CHL}$, and $\mathrm{JL}$ acquired the data. $\mathrm{BL}, \mathrm{CHL}$, and NG analyzed the data. All authors helped interpret the results. CHL and NG provided study materials or patients. BL drafted the manuscript. All authors revised and reviewed this work, and all authors gave their final approval of the submitted manuscript.

\section{Acknowledgements}

Many heartfelt thanks to those who participated in this trial.

\section{References}

1. Piepoli MF, Hoes AW, Agewall S, Albus C, Brotons C, Catapano AL, Cooney MT, Corra U, Cosyns B, Deaton C et al: 2016 European Guidelines on cardiovascular disease prevention in clinical practice: The Sixth Joint Task Force of the European Society of Cardiology and Other Societies on Cardiovascular Disease Prevention in Clinical Practice (constituted by representatives of 10 societies and by invited experts)Developed with the special contribution of the European Association for Cardiovascular Prevention \& Rehabilitation (EACPR). Eur Heart J 2016, 37(29):2315-2381.

2. Roth GA, Forouzanfar MH, Moran AE, Barber R, Nguyen G, Feigin VL, Naghavi M, Mensah GA, Murray CJL: Demographic and epidemiologic drivers of global cardiovascular mortality. The New England journal of medicine 2015, 372(14):1333-1341.

3. Moran AE, Forouzanfar MH, Roth GA, Mensah GA, Ezzati M, Murray CJL, Naghavi M: Temporal trends in ischemic heart disease mortality in 21 world regions, 1980 to 2010: the Global Burden of Disease 2010 study. Circulation 2014, 129(14):1483-1492.

4. Finucane MM, Stevens GA, Cowan MJ, Danaei G, Lin JK, Paciorek CJ, Singh GM, Gutierrez HR, Lu Y, Bahalim AN et al: National, regional, and global trends in body-mass index since 1980: systematic analysis of health examination surveys and epidemiological studies with 960 country-years and 9.1 million participants. Lancet (London, England) 2011, 377(9765):557-567.

5. Danaei G, Finucane MM, Lu Y, Singh GM, Cowan MJ, Paciorek CJ, Lin JK, Farzadfar F, Khang Y-H, Stevens GA et al: National, regional, and global trends in fasting plasma glucose and diabetes prevalence since 1980: systematic analysis of health examination surveys and epidemiological studies with 370 country-years and $\mathbf{2 . 7}$ million participants. Lancet (London, England) 2011, 378(9785):31-40. 
6. Brilakis ES, Mashayekhi K, Tsuchikane E, Abi Rafeh N, Alaswad K, Araya M, Avran A, Azzalini L, Babunashvili AM, Bayani B et al: Guiding Principles for Chronic Total Occlusion Percutaneous Coronary Intervention. Circulation 2019, 140(5):420-433.

7. Valgimigli M, Bueno H, Byrne RA, Collet JP, Costa F, Jeppsson A, Juni P, Kastrati A, Kolh P, Mauri L et al: 2017 ESC focused update on dual antiplatelet therapy in coronary artery disease developed in collaboration with EACTS: The Task Force for dual antiplatelet therapy in coronary artery disease of the European Society of Cardiology (ESC) and of the European Association for Cardio-Thoracic Surgery (EACTS). Eur Heart J 2017.

8. Knuuti J, Wijns W, Saraste A, Capodanno D, Barbato E, Funck-Brentano C, Prescott E, Storey RF, Deaton C, Cuisset T et al: 2019 ESC Guidelines for the diagnosis and management of chronic coronary syndromes. Eur Heart J 2020, 41(3):407-477.

9. Hosokawa K, Ohnishi T, Sameshima H, Miura N, Ito T, Koide T, Maruyama I: Analysing responses to aspirin and clopidogrel by measuring platelet thrombus formation under arterial flow conditions. Thromb Haemost 2013, 109(1):102-111.

10. Guthikonda S, Lev El, Kleiman NS: Resistance to antiplatelet therapy. Curr Cardiol Rep 2005, 7(4):242-248.

11. Tourdot BE, Stoveken H, Trumbo D, Yeung J, Kanthi Y, Edelstein LC, Bray PF, Tall GG, Holinstat M: Genetic Variant in Human PAR (Protease-Activated Receptor) 4 Enhances Thrombus Formation Resulting in Resistance to Antiplatelet Therapeutics. Arterioscler Thromb Vasc Biol 2018, 38(7):16321643.

12. Whitley MJ, Henke DM, Ghazi A, Nieman M, Stoller M, Simon LM, Chen E, Vesci J, Holinstat M, McKenzie SE et al: The protease-activated receptor 4 Ala120Thr variant alters platelet responsiveness to low-dose thrombin and protease-activated receptor 4 desensitization, and is blocked by non-competitive P2Y12 inhibition. J Thromb Haemost 2018, 16(12):2501-2514.

13. Peng W-X, Shi X-J, Xu X-Y, Lin Y: Both CYP2C19 and PON1 Q192R Genotypes Influence Platelet Response to Clopidogrel by Thrombelastography in Patients with Acute Coronary Syndrome. Cardiovasc Ther 2019, 2019:3470145.

14. Mahdieh N, Rabbani A, Firouzi A, Zahedmehr A, Hoseinimoghaddam M, Saedi S, Sanati H, Basiri H, Noohi F, Rabbani B et al: Clopidogrel Pharmacogenetics in Iranian Patients Undergoing Percutaneous Coronary Intervention. Cardiovasc Toxicol 2018, 18(5):482-491.

15. Blair TA, Moore SF, Hers I: Circulating primers enhance platelet function and induce resistance to antiplatelet therapy. J Thromb Haemost 2015, 13(8):1479-1493.

16. Chao J, Dai Y, Verpoorte R, Lam W, Cheng Y-C, Pao L-H, Zhang W, Chen S: Major achievements of evidence-based traditional Chinese medicine in treating major diseases. Biochem Pharmaco/2017, 139:94-104.

17. Liang B, Zou F-H, Fu L, Liao H-L: Chinese Herbal Medicine Dingji Fumai Decoction for Ventricular Premature Contraction: A Real-World Trial. BioMed Research International 2020, 2020:5358467. 
18. Liang B, Zhou Y, Fu L, Liao H-L: Antiarrhythmic Mechanisms of Chinese Herbal Medicine Dingji Fumai Decoction. Evid Based Complement Alternat Med 2020, 2020:9185707.

19. Chen R-X, Xiao Y, Chen M-H, He J, Huang M, Hong X, Liu X, Fu T, Zhang J, Chen L: A traditional Chinese medicine therapy for coronary heart disease after percutaneous coronary intervention: a meta-analysis of randomized, double-blind, placebo-controlled trials. Biosci Rep 2018, 38(5).

20. Association WM: World Medical Association Declaration of Helsinki: ethical principles for medical research involving human subjects. JAMA 2013, 310(20):2191-2194.

21. Michelson AD: Platelet function testing in cardiovascular diseases. Circulation 2004, 110(19):e489e493.

22. Patti G, Nusca A, Mangiacapra F, Gatto L, D'Ambrosio A, Di Sciascio G: Point-of-care measurement of clopidogrel responsiveness predicts clinical outcome in patients undergoing percutaneous coronary intervention results of the ARMYDA-PRO (Antiplatelet therapy for Reduction of MYocardial Damage during Angioplasty-Platelet Reactivity Predicts Outcome) study. J Am Coll Cardio/ 2008, 52(14):11281133.

23. Tantry US, Bonello L, Aradi D, Price MJ, Jeong Y-H, Angiolillo DJ, Stone GW, Curzen N, Geisler T, Ten Berg $\mathrm{J}$ et al: Consensus and update on the definition of on-treatment platelet reactivity to adenosine diphosphate associated with ischemia and bleeding. J Am Coll Cardiol2013, 62(24):2261-2273.

24. Chen J-X, Zou X-J: Traditional Chinese medicine diagnostics. Beijing: People's Medical Publishing House; 2016.

25. Zhou J-G, Liang B, Jin S-H, Liao H-L, Du G-B, Cheng L, Ma H, Gaipl US: Development and Validation of an RNA-Seq-Based Prognostic Signature in Neuroblastoma. Front Oncol 2019, 9:1361.

26. Liang B, Qu Y, Zhao Q-F, Gu N: Guanxin V for coronary artery disease: A retrospective study. Biomed Pharmacother 2020, 128:110280.

27. Michelson AD, Bhatt DL: How I use laboratory monitoring of antiplatelet therapy. Blood 2017, 130(6):713-721.

28. Gorog DA, Fuster V: Platelet function tests in clinical cardiology: unfulfilled expectations. J Am Coll Cardiol 2013, 61(21):2115-2129.

29. Bonello L, Tantry US, Marcucci R, Blindt R, Angiolillo DJ, Becker R, Bhatt DL, Cattaneo M, Collet JP, Cuisset $\mathrm{T}$ et al: Consensus and future directions on the definition of high on-treatment platelet reactivity to adenosine diphosphate. J Am Coll Cardiol 2010, 56(12):919-933.

30. Alnasser SMA, Huang W, Gore JM, Steg PG, Eagle KA, Anderson FA, Fox KAA, Gurfinkel E, Brieger D, Klein W et al: Late Consequences of Acute Coronary Syndromes: Global Registry of Acute Coronary Events (GRACE) Follow-up. The American journal of medicine 2015, 128(7):766-775.

31. Alexander KP, Chen AY, Roe MT, Newby LK, Gibson CM, Allen-LaPointe NM, Pollack C, Gibler WB, Ohman EM, Peterson ED: Excess dosing of antiplatelet and antithrombin agents in the treatment of non-ST-segment elevation acute coronary syndromes. JAMA 2005, 294(24):3108-3116.

32. Kappetein AP, Dawkins KD, Mohr FW, Morice MC, Mack MJ, Russell ME, Pomar J, Serruys PWJC: Current percutaneous coronary intervention and coronary artery bypass grafting practices for three- 
vessel and left main coronary artery disease. Insights from the SYNTAX run-in phase. Eur $J$ Cardiothorac Surg 2006, 29(4):486-491.

33. Chen S-L, Han Y-L, Zhang Y-J, Ye F, Liu H-W, Zhang J-J, Xu B, Jiang T-M, Zhou Y-J, Lv S-Z: The anatomic- and clinical-based NERS (new risk stratification) score II to predict clinical outcomes after stenting unprotected left main coronary artery disease: results from a multicenter, prospective, registry study. JACC Cardiovascular interventions 2013, 6(12):1233-1241.

34. Chen B-D, Chen X-C, Yang Y-N, Gao X-M, Ma X, Huang Y, Li X-M, Gai M-T, Liu F, Pan S et al: Apolipoprotein A1 is associated with SYNTAX score in patients with a non-ST segment elevation myocardial infarction. Lipids Health Dis 2019, 18(1):159.

35. Feng L-M, Yang J-Z, Liu W-N, Wang Q, Wang H, Shi L, Fu L, Xu Q, Wang B, Li T: Lipid Biomarkers in Acute Myocardial Infarction Before and After Percutaneous Coronary Intervention by Lipidomics Analysis. Med Sci Monit 2018, 24:4175-4182.

36. Arakawa K, Himeno H, Kirigaya J, Otomo F, Matsushita K, Nakahashi H, Shimizu S, Nitta M, Takamizawa T, Yano $\mathrm{H}$ et al: B-type natriuretic peptide as a predictor of ischemia/reperfusion injury immediately after myocardial reperfusion in patients with ST-segment elevation acute myocardial infarction. Eur Heart J Acute Cardiovasc Care 2016, 5(1):62-70.

37. Hortmann M, Robinson S, Mohr M, Haenel D, Mauler M, Stallmann D, Reinoehl J, Duerschmied D, Peter $\mathrm{K}$, Bode $\mathrm{C}$ et al: Circulating HtrA2 as a novel biomarker for mitochondrial induced cardiomyocyte apoptosis and ischemia-reperfusion injury in ST-segment elevation myocardial infarction. Int J Cardiol 2017, 243:485-491.

38. Fu R, Song C-X, Yang J-G, Wang Y, Li B, Xu H, Gao X, Li W, Liu J, Dou K et al: CAMI-NSTEMI Score China Acute Myocardial Infarction Registry-Derived Novel Tool to Predict In-Hospital Death in Non-ST Segment Elevation Myocardial Infarction Patients. Circ J 2018, 82(7):1884-1891.

39. Song C-X, Fu R, Dou K-F, Yang J, Xu H, Gao X, Li W, Gao G, Zhao Z, Liu J et al: The CAMl-score: A Novel Tool derived From CAMI Registry to Predict In-hospital Death among Acute Myocardial Infarction Patients. Sci Rep 2018, 8(1):9082.

40. Song C-X, Fu R, Li S-D, Yang J, Wang Y, Xu H, Gao X, Liu J, Liu Q, Wang C et al: Simple risk score based on the China Acute Myocardial Infarction registry for predicting in-hospital mortality among patients with non-ST-segment elevation myocardial infarction: results of a prospective observational cohort study. BMJ open 2019, 9(9):e030772.

\section{Figures}




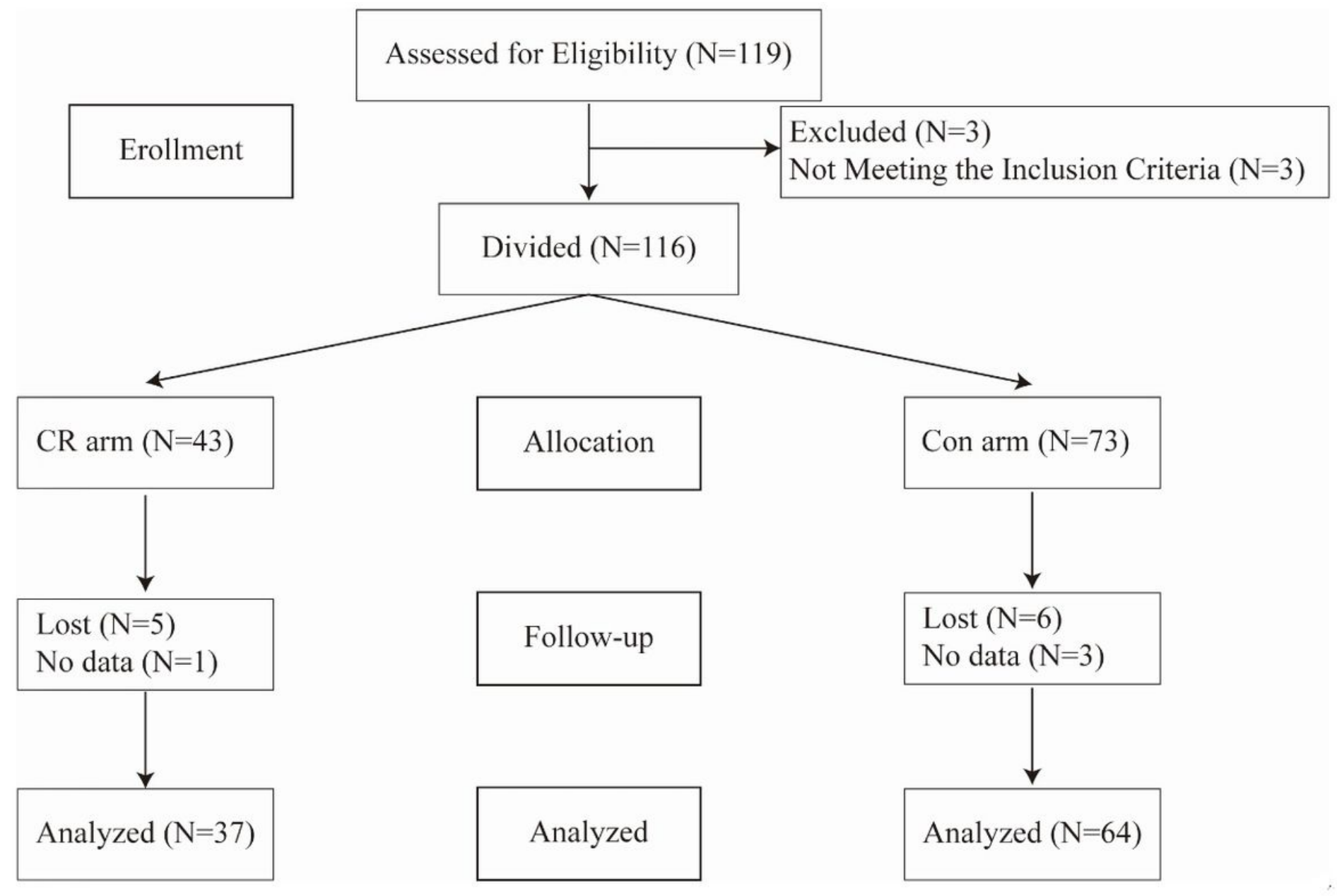

Figure 1

Patient flow diagram. 

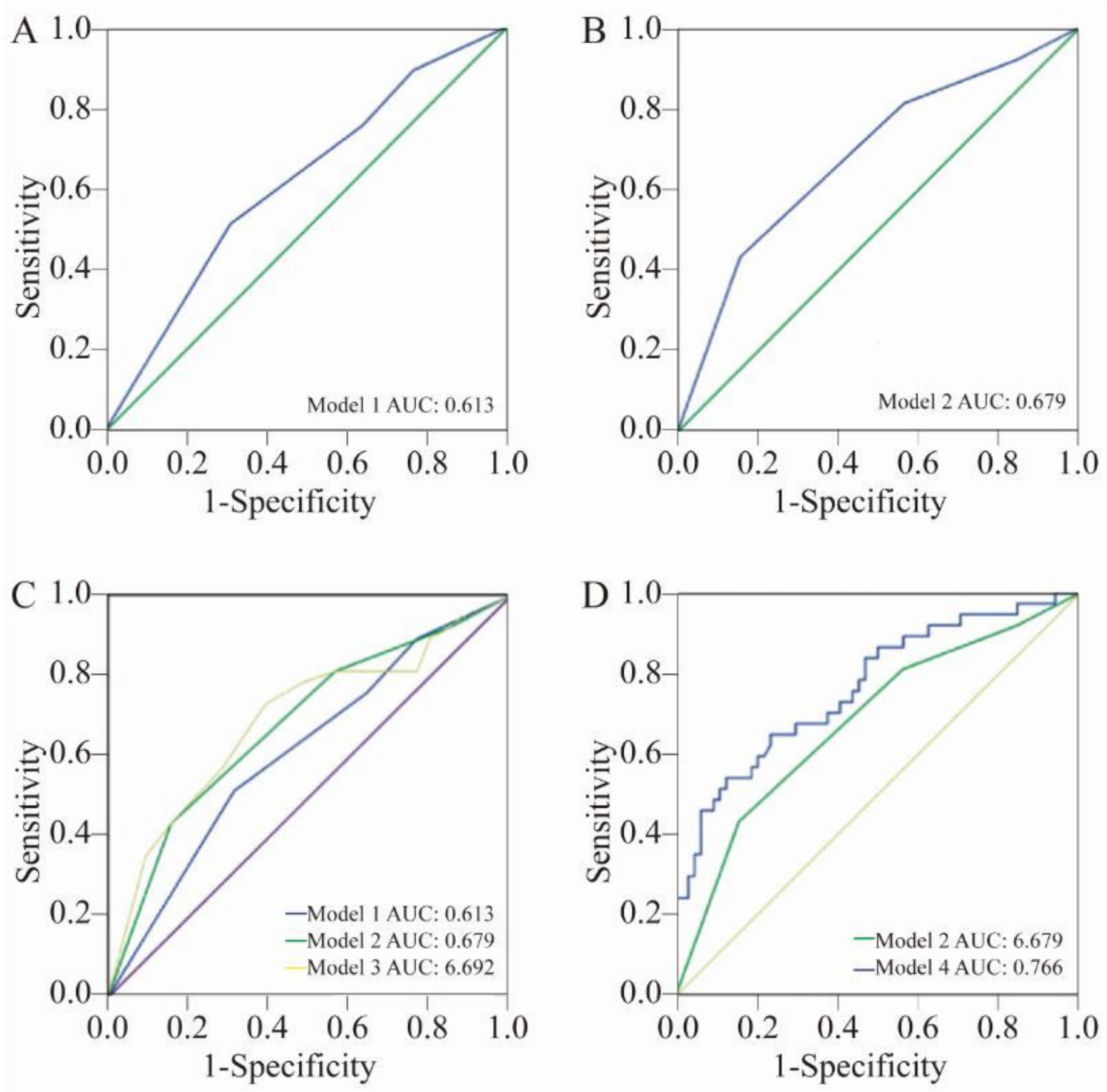

Figure 2

ROC curves for diagnostic signatures. 